\title{
Inhibitive and Adsorption Properties of Ethanol Extract of Seeds and Leaves of Azadirachta Indica on the Corrosion of Mild Steel in $\mathrm{H}_{2} \mathrm{SO}_{4}$
}

\author{
N. O. Eddy, ${ }^{*}$ P. A. P. Mamza \\ Department of Chemistry, Ahmadu Bello University, Nigeria
}

Received 18 December 2008; accepted 4 March 2009

\begin{abstract}
The corrosion of mild steel in $\mathrm{H}_{2} \mathrm{SO}_{4}$ was studied using gravimetric, gasometric and IR methods. The results indicate that the rate of corrosion of mild steel in $\mathrm{H}_{2} \mathrm{SO}_{4}$ increases with increase in the concentration of the acid and that ethanol extracts of the seeds and leaves of Azadirachta indica inhibit the corrosion of mild steel in $\mathrm{H}_{2} \mathrm{SO}_{4}$. Inhibition efficiencies of the leaves and seeds extract range from 82.62 to $94.24 \%$ and from 60.55 to $84.78 \%$, respectively. The inhibition potential of these extracts is attributed to the presence of tannin, saponin, glycoside, anthraquinone, flavonone and other phytochemicals in the extracts. IR study confirms that the inhibitors are adsorption inhibitors and the adsorption of the inhibitors on mild steel surface is exothermic, spontaneous and consistent with the assumptions of Flory-Huggins adsorption isotherm. Based on the values of the activation, free energy of adsorption and the variation of inhibition efficiency with temperature, a physical adsorption mechanism is proposed for the adsorption of ethanol extract of leaves and seeds of Azadirachta indica on the surface of mild steel.
\end{abstract}

Keywords: corrosion, inhibition, Azadirachta indica leaves and seeds.

\section{Introduction}

Corrosion of metals is a serious environmental problem that has been given adequate attention in the oil and gas industries because, during industrial processes such as acid cleaning and etching, metal surfaces are often made to come in contact with acidic medium, indicating that the use of inhibitors in necessary [1-3]. Although there are numerous options for controlling the corrosion of metals, the use of inhibitors is one of the best methods of protecting metals against corrosion. An inhibitor can be chosen from compounds that have

\footnotetext{
* Corresponding author. E-mail address: nabukeddy@yahoo.com
} 
hetero atoms in their aromatic ring system or synthesized from cheap raw materials [4-8]. However, the problem of finding an inhibitor that has little or no impact on the environment has attracted numerous researches in recent times [9]. Green corrosion inhibitors are biodegradable and do not contain heavy metals or other toxic compounds [10]. Most green corrosion inhibitors are obtained from ethanol, aqueous, acid, methanol, or formaldehyde extract of plant materials [11]. The successful use of naturally occurring substances to inhibit the corrosion of metals in acidic and alkaline environments has been reported by some research groups [12-19]. The present study is aimed at investigating the adsorption and inhibitive properties of ethanol extract of leaves and seeds of Azadirachta indica for the corrosion of mild steel in $\mathrm{H}_{2} \mathrm{SO}_{4}$ solutions.

Azadirachta indica (neem) is a plant originated from India. Grown for ornamental purpose and as a wind breaker, it is a member of the families Maliaceae. The plant has been well studied because of its medicinal and insecticidal properties. It has some active ingredients such as azadiraction and limonoids, which are toxic to over 500 species of insects, including the Myzus persicae (aphids). Beyond all the possible pesticides and pharmaceuticals, neem provides many useful and valuable common-place materials. For instance, oil extracted from the seed goes into soaps, waxes and lubricants, as well as into fuels for lighting and heating. The solid residue left after the oil is removed from the kernels is employed as fertilizer and soil amendment. In addition, wood from the trees is valued for construction, cabinetry and fuel. The bark is tapped for gum and extracted for tannins and dental-care products. The leaves are sometimes used for emergency livestock feed. They are also extensively used for dressing unhealthy wounds and ulcers, and also as a febrifuge. Their insectrepellent properties for preservation of woolens, etc. are well known.

\section{Materials and methods \\ Materials}

Materials used for the study were mild steel sheet of composition (wt \%) Mn (0.6), P (0.36), $\mathrm{C}(0.15)$ and $\mathrm{Si}(0.03)$ and the rest Fe. The sheet was mechanically pressed cut to form different coupons, each of dimension, $5 \times 4 \times 0.11 \mathrm{~cm}$. Each coupon was degreased by washing with ethanol, rinsed with acetone and allowed to dry in the air before preservation in a desiccator. All reagents used for the study were analar grade and double distilled water was used for their preparation.

\section{Extraction of plants}

Leaves and seeds of Azadirachta indica were obtained from the Akwa Ibom State Botanical garden in Uyo, South-South Nigeria. The respective samples were dried, grounded and soaked in a solution of ethanol for 48 hours. After 48 hours, the samples were cooled and filtered. The filtrates were further subjected to evaporation at $352 \mathrm{~K}$ in order to leave the sample free of the ethanol. The stock solutions of the extract so obtained were used in preparing different concentrations of the extract by dissolving $0.1,0.2,0.3,0.4$ and $0.5 \mathrm{~g}$ of the 
extract in $1 \mathrm{~L}$ of $2.5 \mathrm{M} \mathrm{H}_{2} \mathrm{SO}_{4}$ for gasometric analysis. For gravimetric analysis, similar concentrations were prepared by dissolving $0.1,0.2,0.3,0.4$ and $0.5 \mathrm{~g}$ of the extract in $1 \mathrm{~L}$ of $0.1 \mathrm{M} \mathrm{H}_{2} \mathrm{SO}_{4}$.

\section{Chemical analysis}

Phytochemical analysis of the ethanol and aqueous extracts of Azadirachta indica leaves and seeds was carried out according to the method reported by Ndukwe et al. [20]. The pulverized plant materials (325.60 g) were defatted using redistilled petroleum spirit $(333-353 \mathrm{~K})$ of fatty acid and their derivatives. The defatted pulverized plant materials were then successively and exhaustively extracted with ethanol. Frothing and $\mathrm{Na}_{2} \mathrm{CO}_{3}$ tests were used for the identification of saponin, bromine water, ferric chloride tests were used for the identification of tannin, and Leberman's and Salkowski's tests were used for the identification of cardiac glycodises, while dragendorf, Hagger and Meyer reagent tests were used for the identification of alkaloid.

\section{Infra red analysis}

IR analyses of ethanol extract of the seeds and leaves of Azadirachta indica and that of the corrosion products (in the absence and presence of ethanol extract of seeds and leaves of Azadirachta indica) were carried out using BUCK model $500 \mathrm{M}$ infra red spectrophotometer. The sample was prepared using $\mathrm{KBr}$ and the analysis was done by scanning the sample through a wave number range of 400 to $4000 \mathrm{~cm}^{-1}$.

\section{Gasometric method}

Gasometric methods were carried out at 303 and $333 \mathrm{~K}$ as described in the literature [21]. From the volume of hydrogen gas evolved per minute, inhibition efficiency $(\% \mathrm{I})$ and degree of surface coverage $(\theta)$ were calculated using equations 1 and 2, respectively:

$$
\begin{gathered}
\% \mathrm{I}=\left(1-\frac{V_{H t}^{1}}{V_{H t}^{o}}\right) x 100 \\
\theta=\% \mathrm{I} / 100=\left(1-\frac{V_{H t}^{l}}{V_{H t}^{o}}\right)
\end{gathered}
$$

where $V_{H t}^{1}$ is the volume of $\mathrm{H}_{2}$ gas evolved at time ' $\mathrm{t}$ ' for inhibited solution and $V_{H t}^{o}$ for uninhibited solution.

\section{Gravimetric analysis}

In gravimetric experiment, a previously weighed mild steel coupon was completely immersed in $250 \mathrm{~mL}$ of the respective test solution in an open beaker. The beaker was inserted into a water bath maintained at $303 \mathrm{~K}$. After every 24 hours of immersion, each sample was withdrawn from the test solution, washed in a solution containing $50 \% \mathrm{NaOH}$ and $100 \mathrm{~g} / \mathrm{L}$ of zinc dust. The washed 
sample was dried with acetone before re-weighing. The difference in weight for a period of $168 \mathrm{~h}$ was taken as total weight loss. From the weight loss results, the inhibition efficiency $(\% \mathrm{I})$ of the inhibitor, degree of surface coverage and corrosion rates were calculated using equations 3, 4 and 5, respectively:

$$
\begin{gathered}
\% \mathrm{I}=\left(1-\mathrm{W}_{1} / \mathrm{W}_{2}\right) \times 100 \\
\theta=1-\mathrm{W}_{1} / \mathrm{W}_{2} \\
\mathrm{CR}\left(\mathrm{gh}^{-1} \mathrm{~cm}^{-2}\right)=\mathrm{W} / \mathrm{At}
\end{gathered}
$$

where $\mathrm{W}_{1}$ and $\mathrm{W}_{2}$ are the weight losses $\left(\mathrm{g} / \mathrm{dm}^{3}\right)$ for mild steel in the presence and absence of inhibitor in $\mathrm{H}_{2} \mathrm{SO}_{4}$ solution, respectively, $\theta$ is the degree of surface coverage of the inhibitor, $\mathrm{A}$ is the area of the mild steel coupon (in $\mathrm{cm}^{2}$ ), $\mathrm{t}$ is the time of immersion (in hours) and $\mathrm{W}$ is the weight loss of mild steel after time $\mathrm{t}$.

\section{Results and discussions}

Figs. 1 and 2 show the variation of weight loss with time for the corrosion of mild steel in $0.1 \mathrm{M} \mathrm{H}_{2} \mathrm{SO}_{4}$ (at $303 \mathrm{~K}$ ) containing various concentrations of ethanol extracts of leaves and seeds of Azadirachta indica. The figures revealed that the weight loss of mild steel in $\mathrm{H}_{2} \mathrm{SO}_{4}$ increases with increase in the time of contact, but decreases with increase in the concentration of ethanol extract of the leaves and seeds of Azadirachta indica, indicating that these extracts inhibit the corrosion of mild steel in $\mathrm{H}_{2} \mathrm{SO}_{4}$. At $333 \mathrm{~K}$, the values obtained for weight loss were relatively higher than the values obtained at $303 \mathrm{~K}$, indicating that the rate of corrosion of mild steel in $\mathrm{H}_{2} \mathrm{SO}_{4}$ increased with increase in temperature.

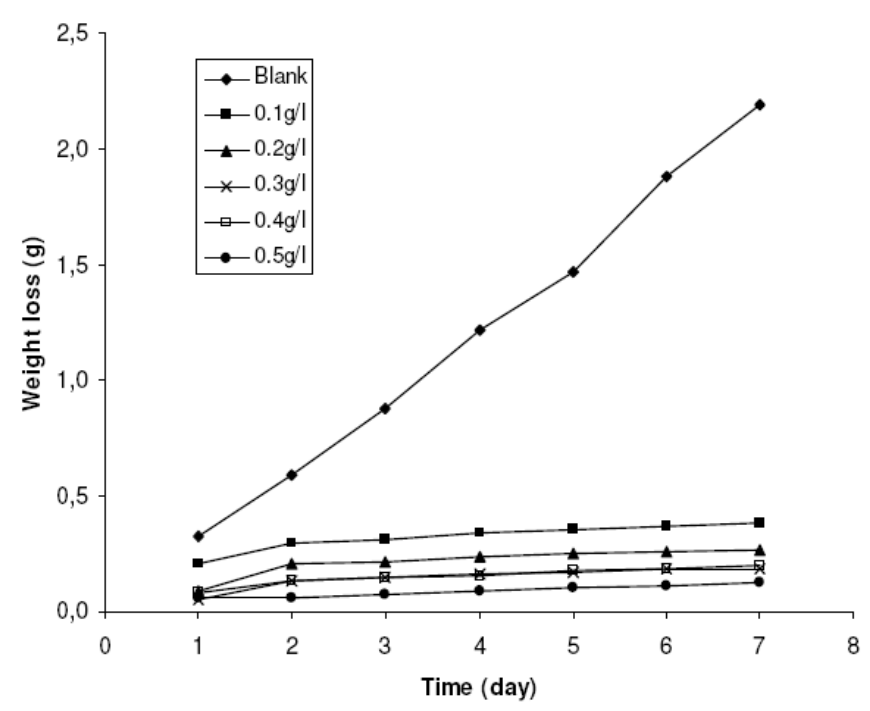

Figure 1. Variation of weight loss of mild steel with time for the corrosion of mild steel in $\mathrm{H}_{2} \mathrm{SO}_{4}$ containing various concentrations of ethanol extract of Azadirachta indica leaves at $303 \mathrm{~K}$. 


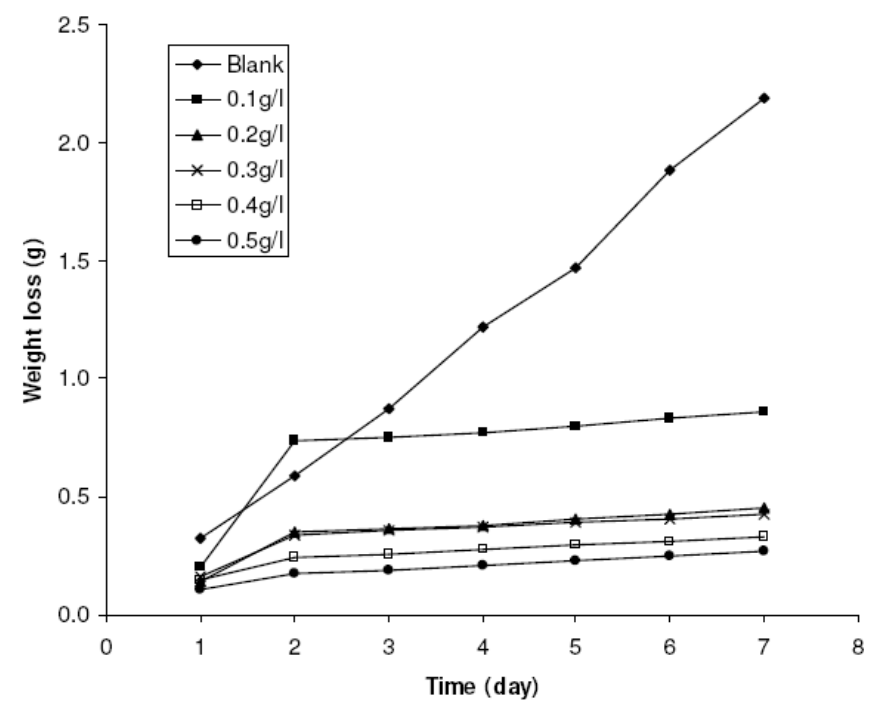

Figure 2. Variation of weight loss with time for the corrosion of mild steel in $\mathrm{H}_{2} \mathrm{SO}_{4}$ containing various concentrations of ethanol extract of Azadirachta indica seeds at 303 $\mathrm{K}$.

Values of the corrosion rates of mild steel (in the absence and presence of ethanol extract of leaves and seeds of Azadirachta indica) and inhibition efficiencies of ethanol extracts of leaves and seeds of Azadirachta indica are recorded in Table 1.

Table 1. Corrosion rates of mild steel and inhibition efficiencies of ethanol extract of leaves and seeds of Azadirachta indica.

\begin{tabular}{|c|c|c|c|c|c|}
\hline \multirow{4}{*}{$\begin{array}{l}\text { Con. } \\
\text { (g/L) }\end{array}$} & \multicolumn{5}{|c|}{ Ethanol extract of Azadirachta indica leaves } \\
\hline & \multicolumn{4}{|c|}{ Gravimetric method } & \multirow{3}{*}{$\begin{array}{c}\text { Gasometric method } \\
\% \text { I } \\
303 \mathrm{~K}\end{array}$} \\
\hline & \multicolumn{2}{|c|}{ CR $\times 10^{-5}\left(\mathrm{gh}^{-1} \mathrm{~cm}^{-2}\right)$} & \multicolumn{2}{|c|}{$\%$ I } & \\
\hline & $303 \mathrm{~K}$ & $333 \mathrm{~K}$ & $303 \mathrm{~K}$ & $333 \mathrm{~K}$ & \\
\hline & 65.10 & 174. 56 & - & - & - \\
\hline 0.1 & 11.3 & 62.44 & 82.62 & 64.23 & 86.43 \\
\hline 0.2 & 7.94 & 53.40 & 87.80 & 69.41 & 86.76 \\
\hline 0.3 & 5.6 & 46.94 & 91.40 & 73.11 & 90.01 \\
\hline 0.4 & 5.85 & 46.24 & 91.01 & 73.51 & 90.08 \\
\hline 0.5 & 3.75 & 45.54 & 94.24 & 73.91 & 92.34 \\
\hline
\end{tabular}

\begin{tabular}{|c|c|c|c|c|c|}
\hline \multirow{4}{*}{$\begin{array}{l}\text { Con. } \\
\text { (g/L) }\end{array}$} & \multicolumn{5}{|c|}{ Ethanol extract of Azadirachta indica leaves } \\
\hline & \multicolumn{4}{|c|}{ Gravimetric method } & \multirow{3}{*}{$\begin{array}{c}\text { Gasometric method } \\
\% \text { I } \\
303 \mathrm{~K}\end{array}$} \\
\hline & \multicolumn{2}{|c|}{$\operatorname{CR} \times 10^{-5}\left(\mathrm{gh}^{-1} \mathrm{~cm}^{-2}\right)$} & \multicolumn{2}{|c|}{$\% \mathbf{I}$} & \\
\hline & $303 \mathrm{~K}$ & $333 \mathrm{~K}$ & $303 \mathrm{~K}$ & $333 \mathrm{~K}$ & \\
\hline & 65.10 & 174. 56 & - & - & - \\
\hline 0.1 & 11.3 & 100.49 & 60.55 & 42.43 & 62.33 \\
\hline 0.2 & 7.94 & 67.33 & 79.34 & 61.43 & 73.24 \\
\hline 0.3 & 5.60 & 63.85 & 80.45 & 63.42 & 81.45 \\
\hline 0.4 & 5.85 & 56.85 & 87.66 & 67.43 & 70.32 \\
\hline 0.5 & 3.75 & 52.00 & 84.78 & 70.21 & 74.32 \\
\hline
\end{tabular}


Values of inhibition efficiency obtained from gasometric method correlated strongly with those obtained from gravimetric method $(r=0.9256$ and 0.6536 for the seed and leave extracts, respectively). The results also reveal that the inhibition efficiencies of ethanol extract of leaves and seeds of Azadirachta indica increased with increase in the concentration of the extracts, but decreased with increase in temperature, suggesting that these extracts are adsorption inhibitors and that the mechanism of adsorption is physical adsorption. Also, the corrosion rates of mild steel in the presence of ethanol extract of seeds and leaves of Azadirachta indica were found to decrease with increase in the concentration of the extracts, indicating that these extracts retarded the corrosion of mild steel in $\mathrm{H}_{2} \mathrm{SO}_{4}$ [21].

Fig. 3 shows a histogram, comparing the inhibition efficiencies of ethanol extract of leaves and seeds of Azadirachta indica with concentration.

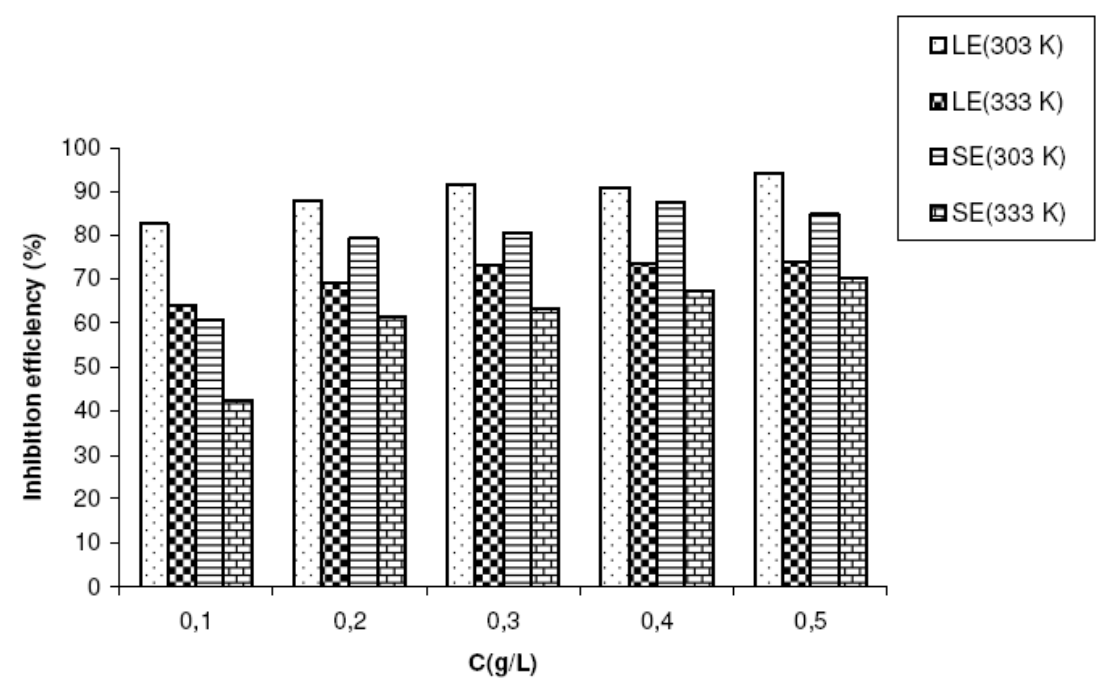

Figure 3. Variation of inhibition efficiencies of ethanol extracts of seed and leaves of Azadirachta indica with concentration.

From Fig. 3, it is seen that values of inhibition efficiency of ethanol extract of Azadirachta indica leaves are higher than the values obtained for ethanol extract of Azadirachta indica seeds, indicating that ethanol extract of the leaves inhibits the corrosion of mild steel more than the seed extract. The difference in inhibition efficiencies of the two extracts may be due to the difference in their phytochemical constituents. Eddy and Ebenso [9] noted that the phytochemical constituents of plant extract, such as saponnin, tannin, alkaloid, glycoside, anthraquinone and flavanoid, are the major factors that determine the inhibition efficiency of the plant extract. Table 2 shows the phytochemical constituents of ethanol extract of leaves and seeds of Azadirachta indica. 
Table 2. Phytochemical composition of ethanol extract of Azadirachta indica leaves and seeds.

\begin{tabular}{|c|c|c|}
\hline Phytochemicals & Leaves & Seeds \\
\hline Saponin & +++ & ++ \\
\hline Tannin & +++ & ++ \\
\hline Phlobatanin & ++ & + \\
\hline Anthraquinone & + & - \\
\hline Cardiac glycosides & +++ & +++ \\
\hline Flavanoid & + & + \\
\hline Terpene & +++ & +++ \\
\hline Alkaloid & +++ & ++ \\
\hline
\end{tabular}

- = absent, + present in trace quantity, $++=$ moderately present, $+++=$ present in large quantity.

The activation energies for the adsorption of ethanol extract of Azadirachta indica on the surface of mild steel were calculated using the Arrhenius equation [22-26]

$$
\mathrm{CR}=\mathrm{A} \exp \left(-\mathrm{E}_{\mathrm{a}} / \mathrm{RT}\right)
$$

Within the temperature range of $303\left(\mathrm{~T}_{1}\right)$ to $333 \mathrm{~K}\left(\mathrm{~T}_{2}\right)$, equation 6 can also be written as follows:

$$
\log \left(\mathrm{CR}_{2} / \mathrm{CR}_{1}\right)=\mathrm{E}_{\mathrm{a}} / \mathrm{R}\left(1 / \mathrm{T}_{1}-1 / \mathrm{T}_{2}\right)
$$

where $E_{a}$ is the activation energy, $C_{1}$ and $C_{2}$ are the corrosion rates at the temperatures $\mathrm{T}_{1}(303 \mathrm{~K})$ and $\mathrm{T}_{2}(333 \mathrm{~K})$, respectively. Values of $\mathrm{E}_{\mathrm{a}}$ calculated from equation 7 are recorded in Table 3 . These values were found to range from 47.86 to $69.91 \mathrm{~kJ} / \mathrm{mol}$ and from 49.97 to $73.62 \mathrm{~kJ} / \mathrm{mol}$ for ethanol extract of leaves and seeds of Azadirachta indica, respectively. The observed results indicated that the adsorption of these extracts is consistent with the mechanism of physical adsorption. For a physical adsorption mechanism, the activation energy should be less than $80 \mathrm{KJ} / \mathrm{mol}$, as observed in the present study [27 - 29]. Also, the values of $\mathrm{E}_{\mathrm{a}}$ obtained in the presence of ethanol extract of leaves and seeds of Azadirachta indica were higher than the value of $27.62 \mathrm{KJ} / \mathrm{mol}$ obtained for the blank, indicating that the extracts retarded the corrosion of mild steel in $\mathrm{H}_{2} \mathrm{SO}_{4}$. The activation energies were also observed to increase with increasing in the concentration of the extracts, indicating that there is increasing ease of adsorption of the inhibitors with increasing concentration.

The heat of adsorption $\left(\mathrm{Q}_{\mathrm{ads}}\right)$ of ethanol extract of leaves and seeds of Azadirachta indica on the surface of mild steel was calculated using equation 8 [12]

$$
Q_{a d s}=2.303 R\left[\log \left(\frac{\theta_{2}}{1-\theta_{2}}\right)-\log \left(\frac{\theta_{1}}{1-\theta_{1}}\right)\right] x\left(\frac{T_{1 X} T_{2}}{T_{2}-T_{1}}\right) k J m o l^{-1}
$$

where $\theta_{1}$ and $\theta_{2}$ are the degrees of surface coverage at the temperatures, $\mathrm{T}_{1}(303$ $\mathrm{K})$ and $\mathrm{T}_{2}(333 \mathrm{~K})$, respectively. Values of $\mathrm{Q}_{\mathrm{ads}}$ calculated from equation 8 are recorded in Table 3. These values are negative, indicating that the adsorption of 
ethanol extract of leaves and seeds of Azadirachta indica on the surface of mild steel is exothermic.

Table 3: Activation energies and heat of adsorption of ethanol extract of leaves and seeds of Azadirachta indica on the surface of mild steel.

\begin{tabular}{|c|c|c|c|c|}
\hline \multirow{2}{*}{$\begin{array}{c}\text { Conc. } \\
(\mathbf{g} / \mathbf{L})\end{array}$} & \multicolumn{2}{|c|}{$\mathbf{E}_{\mathbf{a}}(\mathbf{k J} / \mathbf{m o l})$} & \multicolumn{2}{c|}{$\mathbf{Q}_{\text {ads }}(\mathbf{k J} / \mathbf{m o l})$} \\
\cline { 2 - 5 } & Leave extract & Seed extract & Leave extract & Seed extract \\
\hline Blank & 27.62 & 27.62 & - & - \\
\hline 0.1 & 47.86 & 49.97 & -20.42 & -15.39 \\
\hline 0.2 & 53.36 & 58.37 & -24.21 & -18.46 \\
\hline 0.3 & 59.53 & 64.89 & -28.60 & -18.13 \\
\hline 0.4 & 57.88 & 63.67 & -27.15 & -25.86 \\
\hline 0.5 & 69.91 & 73.62 & -36.78 & -18.04 \\
\hline
\end{tabular}

The adsorption characteristic of the inhibitors was also studied by fitting data obtained for degree of surface coverage into different adsorption isotherms. The tests reveal that the adsorption of ethanol extract of leaves and seeds of Azadirachta indica on the surface of mild steel is best described by FloryHuggins adsorption isotherm.

The assumptions of Flory-Huggins adsorption isotherm can be expressed as follows,

$$
\log (\theta / C)=\log \mathrm{K}+\mathrm{x} \log (1-\theta)
$$

where $\mathrm{x}$ is the number of inhibitor molecules occupying one site (or the number of water molecules replaced by one molecule of the inhibitor). The plots of $\log (\theta / C)$ versus $\log (1-\theta)$ (Fig. 4) were linear, confirming the application of FloryHuggins isotherm to the adsorption of ethanol extract of leaves and seeds of Azadirachta indica on the surface of mild steel. Values of the adsorption parameters deduced from Flory-Huggins plots are presented in Table 4. The values of $x$ obtained for the leave extract were higher than those obtained for the seed extract, suggesting that the adsorption behaviour of the leave extract is better than that of the seed extract.

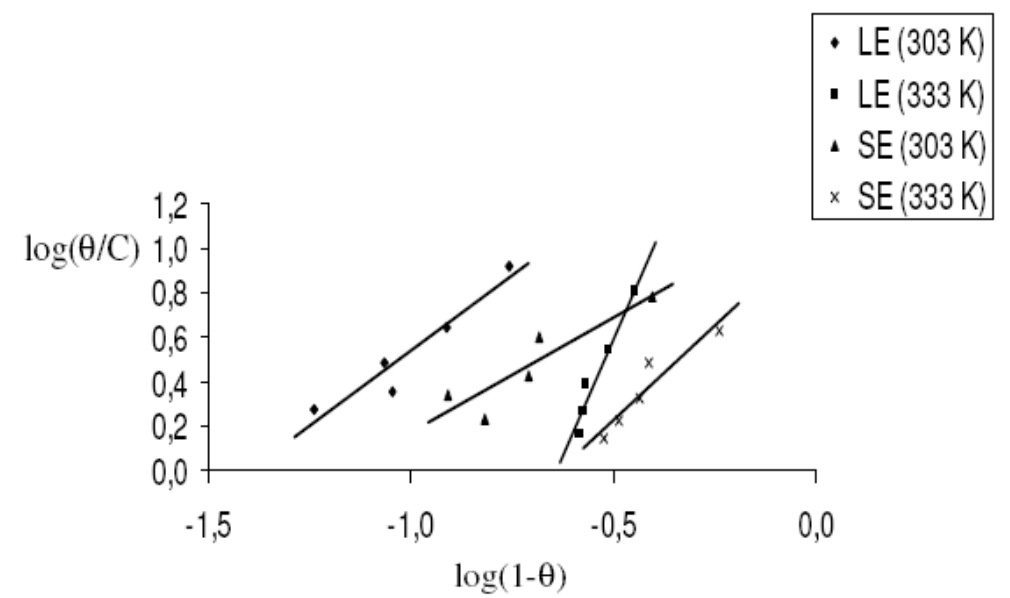

Figure 4. Flory-Huggins isotherm for the adsorption of ethanol extract of leaves and seeds of Azadirachta indica on the surface of mild steel. 
Table 4. Flory-Huggins adsorption parameters for the adsorption of ethanol extract of leaves (LE) and seeds (SE) of Azadirachta indica on the surface of mild steel.

\begin{tabular}{|c|c|c|c|c|c|}
\hline \multirow{5}{*}{ 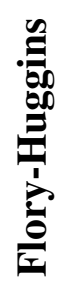 } & & $\log K$ & $\mathbf{X}$ & $\Delta \mathrm{G}_{\mathrm{ads}}(\mathrm{KJ} / \mathrm{mol})$ & $\mathbf{R}^{2}$ \\
\hline & LE (303 K) & 1.8993 & 1.3574 & -21.11 & 0.9151 \\
\hline & LE (333 K) & 2.6904 & 4.1917 & -28.25 & 0.9466 \\
\hline & SE (303 K) & 1.2044 & 1.0338 & -17.08 & 0.8164 \\
\hline & SE (333 K) & 1.0659 & 1.6712 & -17.89 & 0.8917 \\
\hline
\end{tabular}

Inhibition efficiency depends on several factors, such as the number of adsorption sites and their charge density, $\mathrm{pH}$ of the corrodent, molecular size, heat of hydrogenation, mode of interaction with the metal surface and the formation of metallic complexes [29]. Due to adsorption, inhibitor molecules block the reaction sites and reduce the rate of corrosion. The inhibitor molecules inhibit the corrosion of mild steel by adsorption on the mild steel-solution surface; the adsorption provides the information about the interaction around the adsorbed molecules themselves as well as their interaction with mild steel surface. The inhibition of the corrosion of mild steel by ethanol extracts of seeds and leaves of Azadirachta indica can partly be attributed to substitutional adsorption involving Fe in mild steel and the inhibitor (inh) as follows,

$$
\mathrm{Fe}+\mathrm{Inh} \leftrightarrows \mathrm{Fe}^{-}(\mathrm{Inh})_{\mathrm{ads}} \leftrightarrows \mathrm{Fe}^{\mathrm{n}+}+\mathrm{ne}^{-}+\mathrm{Inh}
$$

The adsorbed layer combats the action of the acid solution and enhances protection of the metal surface. When there is sufficient $\mathrm{Fe}^{-}(\mathrm{Inh}\}_{\text {ads }}$ to cover the metal surface (if the inhibitor concentration was low or the adsorption rate was slow), metal dissolution would take place at sites on the mild steel surface which are free of Fe-(Inh) ads. With high inhibitor concentration a compact and coherent inhibitor over layer is formed on the surface of mild steel thereby reducing the extent of chemical attack on the metal [8].

The equilibrium constant of adsorption of ethanol extract of leaves and seeds of Azadirachta indica on the surface of mild steel is related to the free energy of adsorption $\left(\Delta \mathrm{G}_{\mathrm{ads}}\right)$ according to equation 11 [18-20]:

$$
\Delta \mathrm{G}_{\mathrm{ads}}=-2.303 \mathrm{RT} \log (55.5 \mathrm{~K})
$$

where $\mathrm{R}$ is the gas constant, $\mathrm{T}$ is the temperature, $\mathrm{K}$ is the equilibrium constant of adsorption and 55.5 is the molar concentration of $\mathrm{H}_{2} \mathrm{SO}_{4}$. Values of $\mathrm{K}$ obtained from Flory-Huggins adsorption isotherm were substituted into equation 11 to obtain values of $\Delta \mathrm{G}_{\mathrm{ads}}$ which are also recorded in Table 4 . These values are negatively lower than the threshold value of $-40 \mathrm{KJ} / \mathrm{mol}$ required for chemical adsorption, hence the adsorption of ethanol extract of leaves and seeds of Azadirachta indica on the surface of mild steel is spontaneous and favours the mechanism of physical adsorption. Also, the average value of $\Delta \mathrm{G}_{\mathrm{ads}}$ obtained for the adsorption of the ethanol extract of Azadirachta indica leaves was greater than the value for the seed, indicating that the leaves extract is better adsorbed on the surface of mild steel than the seeds. Generally, the more negative the value of $\Delta \mathrm{G}_{\mathrm{ads}}$, the stronger the strength of adsorption, as observed in this study. 
Fig. 5 shows the IR spectrum of the corrosion product of mild steel without the inhibitor. The spectrum reveals that the corrosion product is not IR active. Figs. 6 and 7 present the IR spectrum of ethanol extract of Azadirachta indica leaves and seeds, respectively. The assigned functional groups are recorded in Tables 5 and 6 , respectively.

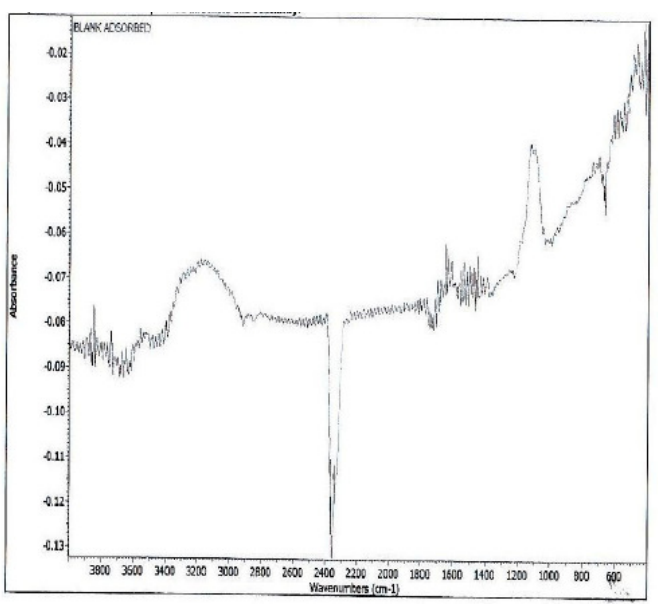

Figure 5. IR spectrum of the corrosion product of mild steel.

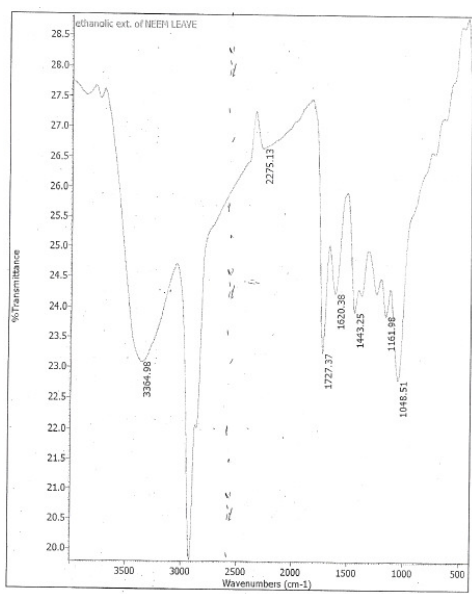

Figure 6. IR spectrum of ethanol extract of the leaves of Azadirachta indica.

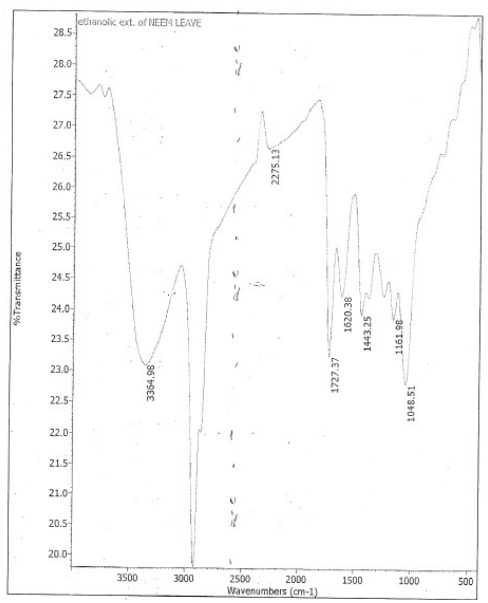

Figure 7. IR spectrum of ethanol extract of the seeds of Azadirachta indica. 
Table 5: Functional groups assigned to adsorption of ethanol extract of leaves of Azadirachta indica and the corrosion product when the extract is used as inhibitor.

\begin{tabular}{|c|c|c|c|c|l|}
\hline \multicolumn{4}{|c|}{ Ethanol extract } & \multicolumn{3}{|c|}{ Corrosion product } \\
\hline $\begin{array}{c}\text { Wave No } \\
\left(\mathbf{c m}^{-1}\right)\end{array}$ & Height & $\begin{array}{c}\text { Assigned functional } \\
\text { group }\end{array}$ & $\begin{array}{c}\text { Wave No } \\
\left(\mathbf{c m}^{-1}\right)\end{array}$ & Height & Assigned functional group \\
\hline 3364.98 & 23.07 & - -OH stretch & 3213.30 & 6.580 & $\begin{array}{l}\text {-OH stretch, H-bonding } \\
\text { (alcohol, phenol) }\end{array}$ \\
\hline 2926.16 & 19.77 & -CH stretch & 2921.94 & 6.890 & C-H stretch (alkane) \\
\hline 2275.13 & 26.64 & C (triple bond) N stretch & 1103.74 & 7.410 & $\begin{array}{l}\text { C-O stretch (aliphatic } \\
\text { amine) }\end{array}$ \\
\hline 1727.37 & 23.24 & C=O stretch & 881.99 & 8.580 & C-H-oop (aromatic) \\
\hline 1620.38 & 24.23 & N-H bend & & & \\
\hline 1443.25 & & C-C stretch (in ring) & & & \\
\hline 1161.98 & & C-N stretch & & & \\
\hline 1048.51 & 22.80 & C-O stretch & & & \\
\hline
\end{tabular}

Table 6. Functional groups assigned to adsorption of ethanol extract of seeds of Azadirachta indica and the corrosion product when the extract is used as inhibitor.

\begin{tabular}{|c|c|c|c|c|l|}
\hline \multicolumn{3}{|c|}{ Ethanol extract } & \multicolumn{3}{c|}{ Corrosion product } \\
\hline $\begin{array}{c}\text { Wave number } \\
\left(\mathbf{c m}^{-1}\right)\end{array}$ & Position & Bond & $\begin{array}{c}\text { Wave number } \\
\left(\mathbf{c m}^{-1}\right)\end{array}$ & Position & Bond \\
\hline 2922.32 & 2.07 & - OH stretch & 3165.43 & 2.084 & $\begin{array}{l}\text {-OH stretch } \\
\text { (carboxylic acid) }\end{array}$ \\
\hline 1710.95 & 2.81 & C=O stretch & 1669.73 & 9.320 & C=O stretch \\
\hline 1455.35 & 5.18 & C-H bend & 112.93 & 7.625 & C-N stretch \\
\hline 1244.08 & 5.44 & C-N stretch & 880.61 & 7.876 & C-H oop \\
\hline 939.37 & 9.38 & =C-H bend & & & \\
\hline 723.03 & 9.897 & C-H oop & & & \\
\hline
\end{tabular}

Figs. 8 and 9 show the IR spectra of the corrosion product of mild steel when ethanol extract of leaves and seeds of Azadirachta indica, respectively, were used as inhibitors. From the results, it was found that for the leaves extract, the $-\mathrm{OH}$ stretch at $3364.98 \mathrm{~cm}^{-1}$ was shifted to $3213.30 \mathrm{~cm}^{-1}$, the $\mathrm{C}-\mathrm{H}$ stretch at 2926.16 $\mathrm{cm}^{-1}$ was shifted to $2921.94 \mathrm{~cm}^{-1}$, the C-O stretch at 1048.51 was shifted to $1103.74 \mathrm{~cm}^{-1}$, indicating that there is interaction between the inhibitor and the surface of mild steel [29]. Also C (triple bond) N stretch, the N-H bend, the C-C stretch and the $\mathrm{C}-\mathrm{N}$ stretch were missing in the spectrum of the corrosion product, indicating that the inhibitor was adsorbed to the surface of mild steel through these bonds [14]. However, for the seeds extract, the $-\mathrm{OH}$ stretch at $2922.32 \mathrm{~cm}^{-1}$ was shifted to $3165.43 \mathrm{~cm}^{-1}$, the $\mathrm{C}=\mathrm{O}$ stretch at $1710.95 \mathrm{~cm}^{-1}$ was shifted to $1669.73 \mathrm{~cm}^{-1}$, the $\mathrm{C}-\mathrm{N}$ stretch at $1244.08 \mathrm{~cm}^{-1}$ was shifted to 1121.93 $\mathrm{cm}^{-1}$, while the $\mathrm{C}-\mathrm{H}$ oop was shifted from $723.03 \mathrm{~cm}^{-1}$ to $880.61 \mathrm{~cm}^{-1}$, indicating that there is interaction between the inhibitor and the surface of mild steel. Also the $\mathrm{C}-\mathrm{H}$ bend and the $=\mathrm{C}-\mathrm{H}$ bend were missing in the spectrum of the corrosion product, indicating that these bonds must have been used for the adsorption of the inhibitor on the surface of mild steel [29]. 


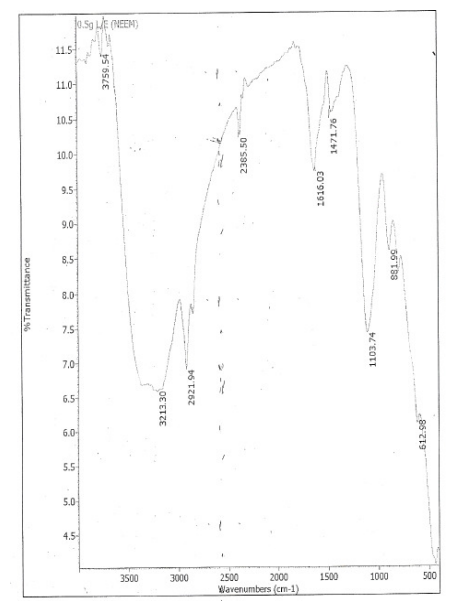

Figure 8. IR spectrum of the corrosion product in the presence of ethanol extract of the leaves of Azadirachta indica.

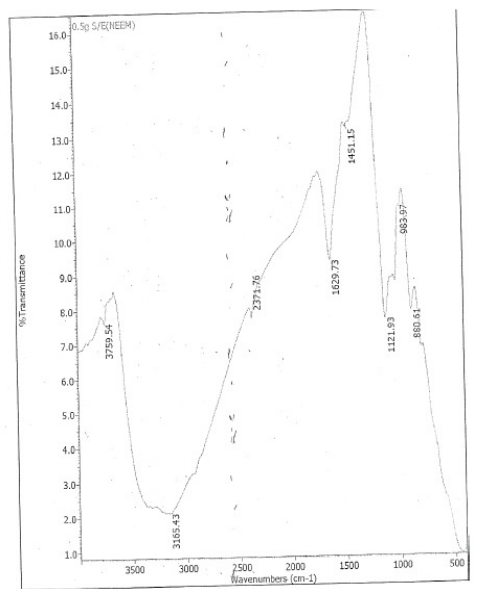

Figure 9. IR spectrum of the corrosion product in the presence of ethanol extract of the seeds of Azadirachta indica.

\section{Conclusion}

From the study, it was concluded that ethanol extract of leaves and seeds of Azadirachta indica are good adsorption inhibitors for the corrosion of mild steel. However, the inhibition efficiency of the leaves is better than that of the seeds. The inhibition of the corrosion of mild steel by ethanol extract of the leaves and seeds of Azadirachta indica is due to the phytochemical constituents of the extract. These phytochemical constituents enhanced the adsorption behaviour of the inhibitors. The adsorption of ethanol extract of the leaves and seeds of Azadirachta indica is spontaneous and occurred according to the mechanism of physical adsorption. The formation of multimolecular layer of adsorption as described by Flory-Huggins adsorption isotherm also supported this assertion. The corrosion product of mild steel is not IR active, but in the presence of ethanol extracts of Azadirachta indica leaves and seeds, the IR spectra of the corrosion product confirmed that these extracts inhibited the corrosion of mild steel by being adsorbed on the surface of mild steel and that there is interaction between the inhibitor and the surface.

In view of the above conclusion, the use of ethanol extracts of seeds and leaves of Azadirachta indica as inhibitors is recommended. 


\section{References}

1. M. Abdallah, Portugaliae Electrochimica Acta 22 (2004) 161.

2. L. Anauda, R.A. Sathiyanathan, S.B. Maruthamuthu, M.C. Selvanayagam, S.B. Mohanan and N.B. Palaniswamy, Indian J. Chem. Tech. 12 (2005) 356.

3. H. Ashassi-Sorkhabi, B. Shaabani, B. Aligholipour and D. Seifzadeh, Appl. Surf. Sci. 252 (2006) 4039.

4. M.A. Bendahou, M.B.E. Benadellah, B.B. Hammouti, Pigment and Resin Technol. 35 (2006) 95.

5. A. Bouyanzer and B. Hammouti, Pigment and Resin Technol. 33 (2004) 287.

6. A. Chetounani, B. Hammouti and M. Benkaddour, Pigment and Resin Technol. 33 (2004) 26.

7. E.E. Ebenso, U.J. Ibok, U.J. Ekpe, S. Umoren, J. Ekerete, O.K. Abiola, N.C. Oforka and S. Martinez, Trans. SAEST 39 (2004) 117.

8. N.O. Eddy, Inhibition of corrosion of mild steel by some antibiotics, Ph.D. Thesis, University of Calabar, 2008.

9. N.O. Eddy and E.E. Ebenso, African J. Pure Appl. Chem. 2(6) (2008) 1.

10. N.O. Eddy and S.A. Odoemelam, Pigment and Resin Technol. 38(2) (2009) 111.

11. A.O. Odiongenyi, S.A. Odoemelam and N.O. Eddy, Portugaliae Electrochimica Acta 27(1) (2009) 33.

12. E.E. Ebenso, N.O. Eddy and A.O. Odiongenyi, Afri. J. Pure and Appl. Chem. 2 (2008) 107.

13. N.O. Eddy, P. Ekwumemgbo and S.A. Odoemelam, Inter. Journal Physical Sciences 3 (2008) 1.

14. N.O. Eddy, S.A. Odoemelam and A.O. Odiongenyi, J. Appl. Electrochem. DOI 10. 1007/s10800-008-9731 (2008).

15. N.O. Eddy, S.A. Odoemelam and N.W. Akpanudoh, J. Chem. Technol. 4 (2008) 1.

16. A.Y. El-Etre, Corros. Sci. 45 (2003) 2485.

17. A.Y. El-Etre, Appl. Surface Sci. 252 (2006) 8521.

18. A.Y. El-Etre, M. Abdallah and Z.E. El-Tantawy, Corros. Sci. 47 (2005) 385.

19. S.A. Odoemelam and N.O. Eddy, J. Surface Sci. Technol. 24 (2008) 1.

20. I.G. Ndukwe, M.O. Achimugu and N.F. Amako, J. Pest, Diseases and Vector Mgt. 6 (2005) 391.

21. S.A. Odoemelam and N.O. Eddy. J. Materials Science 4 (2008) 1.

22. E.E. Oguzie, Corros. Sci. 49 (2007) 1527.

23. P.C. Okafor, V.I. Osabor and E.E. Ebenso, Pigment and Resin Technol. 36 (2007) 299.

24. R.A.I. Sathiyanathan, M.M.C. Essa, S.B. Maruthamuthu, M.A. Selvanayagam and N.B. Palaniswamy, J. Indian Chemical Society 82 (2005) 357.

25. M.G. Sethuraman and P.B. Raja, Pigment and Resin Tech. 34 (2005) 327. 
26. D.S. Sheatty, P. Shetty and H.V.S. Nayak, Journal Chidean Chemical Society 51 (2006) 849.

27. H. Shokry, M. Yuasa, I. Sekine, R.M. Issa, H.Y. El-Baradie and G.K.G. Gomma, Corros. Sci. 40 (1998) 2173.

28. S.A. Umoren, I.B. Obot and E.E. Ebenso, E-Journal of Chemistry. 5 (2008) 355.

29. S.K. Rajappa, T.V. Venkatesha and B.M. Peaveen, Bull. Mater. Sci. 31 (2008) 37. 